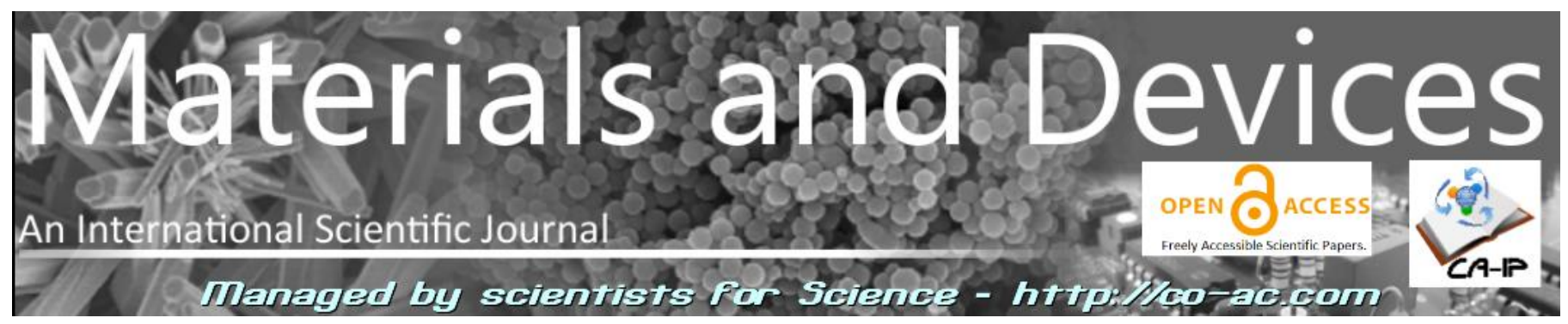

\title{
Characterization and modeling of solar radiation on the ground, application to the estimate of solar potential available on the coast of Nouakchott
}

\author{
Ahmed Sidibba $^{1 *}$, Diene Ndiaye ${ }^{1}$, Sidi Bouhamady ${ }^{2}$, Menny EL Bah ${ }^{2}$ \\ (1) Laboratoire d'Electronique Informatique Télécommunications et Energies \\ Renouvelables, (UGB), Saint-Louis, Sénégal. \\ (2) Unité Energies Renouvelables, Département physique, Université de Nouakchott Al- \\ Aasriya, Nouakchott, Mauritanie. \\ Corresponding author : sidiabaahmed@gmail.com
}

RECEIVED: 21 november 2018 / RECEIVED IN FINAL FORM: 14 february 2019 / ACCEPTED: 17 february 2019

\begin{abstract}
The purpose of this work is to evaluate four empirical models developed in literature such as Ghouard, Perrin Brichambaut, Bird and Hulstrom and Dependent model of the Link trouble factor. The validation of these different theoretical models was carried out using solar global radiation data collected on the Cheikh Zayed Nouakchott power plant. These measurements were carried out at a time step of 5 minutes during the period of one year. (April 1, 2015 to March 31, 2016). The results show that the Ghouard model presents notable performances compared to the other models, with a determination coefficient of $96.2 \%$. This validation also shows that the solar radiation measured and that estimated by the different models have the same pace and have good performance with a coefficient of determination greater than $93 \%$. The available solar potential estimation was carried out using the actual measurements collected on the Cheikh Zayed plant. The results obtained showed that the available solar potential is $5 \mathrm{kWh} / \mathrm{m}^{2} / \mathrm{d}$.
\end{abstract}

Keywords : SOLAR PONTENTIAL, THEORETICAL MODELS, MEASURED DATA, SHEIKH ZAYED PLANT. 


\section{Introduction}

The problem of energy has dominated the global economic and political scenes of the last forty years. The predominant use of fossil fuels such as oil and gas has led to a number of environmental and regional conflicts. The 1973 crisis, known as the energy crisis, has forced the world to think of alternatives to existing conventional resources that are exhaustible and in limited quantities on a global scale. Indeed, fossil fuels tend to be depleted by the high-energy consumption of the world, hence the need to find new energy resources. Renewable energies have a great advantage because they are abundant and inexhaustible. The major limit of these renewable resources remains the high initial investment cost [1] and its random characteristics that require a feasibility analysis of their available potentials. Solar energy occupies, today, one of the most important places among the various resources of renewable energies. The precise knowledge of the available potential of sunshine and its distribution at a given location, however, remains of major importance for the development of solar energy systems and the analysis of their performance. In recent years, many models have been proposed to predict solar radiation. Capderou et al. 1987 [2] proposed a prediction model of solar radiation based essentially on the knowledge of the atmospheric disorder factor. The model makes it possible to determine the different components of the solar radiation (global, diffuse and direct) of a given locality. Zhang et al, 2002 [3] proposed a model for estimating hourly solar radiation in Beijing and Guangzhou. As part of this modeling, the authors considered the influence of the variation of meteorological parameters as temperature, humidity and wind speed on the behavior of solar radiation. Chen et al, 2004 [4] observed, following a study, that the Hargreaves and Allen models are not suitable for estimating global solar radiation for, especially, regions of China. As a result, they suggested another model to improve the estimation of sunshine. The aim of this work is to study different methods for determining global solar radiation on a horizontal plane and then to validate it by comparison with solar radiation measured at the Nouakchott-Mauritania site, which will make it possible to propose the most appropriate model for the prediction of solar radiation. Finally, we make an estimate of available solar energy in Nouakchott in the coastal region.

\section{Data and Methodologies}

\section{Study site}

The site of study located in Nouakchott, the capital of Mauritania according to the coordinates $\left(15.983^{\circ} \mathrm{E}\right.$, $18.153^{\circ} \mathrm{N}$ ). A photovoltaic plant of $15 \mathrm{MWp}$ is installed in this site in 2013. The plant is instrumented by a system of measurements of meteorological parameters such as temperature, solar radiation and wind speed. Figure 1 illustrates the geographical location of the site. The data collected on this system covers the period of one year (April 1, 2015 to March 31, 2016) and is measured every 5 minutes.

\section{Calculation method of available solar energy}

The available solar energy represents the amount of energy received on the ground per unit area $\left(\mathrm{Wh} / \mathrm{m}^{2}\right)$. It can be defined as the integral of the solar power received on the ground during a period of 24 hours. This period is often limited to another period corresponding to the interval from sunrise to sunset. Available daily solar energy can be calculated using following equation: [5].

$$
E_{g}=\int_{L s}^{C s} I_{g}(t) \cdot d t
$$

With, $I_{g}(t)$ indicates the instantaneous solar radiation (power received on the ground per unit area) in $\left(W / \mathrm{m}^{2}\right)$.

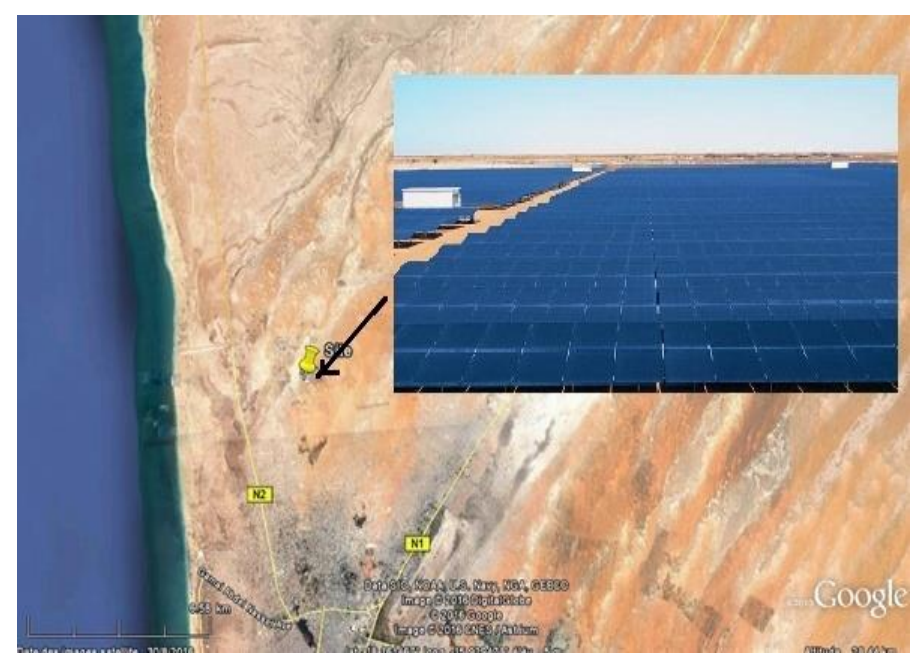

Figure1. Geographical location of the site

\section{Clearness Index}

Another parameter to analyze the feasibility of available solar potential will also be calculated. This is the clearness index kt, which is most often calculated using the following equation:

$$
\mathrm{K}_{\mathrm{t}}=\frac{\mathbf{G}_{\mathrm{o}}}{\mathbf{G}_{\mathrm{h}}}
$$

Where, $\mathrm{G}_{0}$ is the solar energy measured on the ground $\left(\mathrm{kWh} / \mathrm{m}^{2} / \mathrm{d}\right)$ and $\mathrm{G}_{\mathrm{h}}$ is the solar energy measured outside the atmosphere $\left(\mathrm{kWh} / \mathrm{m}^{2} / \mathrm{d}\right)$.

$$
G_{h}=\frac{24 \cdot I_{c s}}{\pi} \cdot\left[1+0,0033 \cdot \cos \left(\frac{360 \cdot n}{365}\right)\right] \cdot X
$$

Where, $\mathrm{n}$ is the day number of the year, the parameter $(X)$ is given by equation (4). 
$X=\left(\cos (\mathrm{L}) \quad \cdot \cos (\delta) \cdot \sin (\omega)+\frac{\pi}{180} \cdot \omega \cdot \sin (\mathrm{L}) \cdot \sin (\delta)\right)$

\section{Modeling of solar radiation}

In this phase of the study, four models will be presented to analyze their performance on the Nouakchott coast using real data collected on this site.

\section{Bird and Hulstrom model}

The direct normal irradiance in this model described by Bird and Hulstrom [6] is in function of absorption and transmittance by the atmospheric components such as of ozone, gas, water and aerosols, and it is given as follows:

$$
I_{n}=0,9751 \cdot I_{s c} \cdot \tau_{r} \cdot \tau_{0} \cdot \tau_{g} \cdot \tau_{w} \cdot \tau_{a}
$$

$\tau_{r}, \tau_{o}, \tau_{g}, \tau_{w}, \tau_{a}$ (dimensionless) are the Rayleigh, ozone, gas, water and aerosols scattering transmittances, respectively. They are given as follows:

$\tau_{r}=\exp \left(-0,0903 \cdot m_{A}{ }^{0,84} \cdot\left(1+m_{A}-m_{A}{ }^{1,01}\right)\right)$

$\tau_{g}=\exp \left(-0,0127 \cdot m_{A}{ }^{0,26}\right)$

$\tau_{w}=1-2,4959 \cdot U_{1}\left[\left(1+79,034 \cdot U_{1}\right)^{0,68258}+6,385 \cdot U_{1}\right]^{-1}$

$\tau_{a}=\exp \left(-K_{a}{ }^{0,873} \cdot\left(1+K_{a}-K_{a}{ }^{0,7808}\right) \cdot m_{A}{ }^{0,9108}\right)$

$\tau_{0}=1-\left[0,1611 \cdot U_{3} \cdot\left(1+139,48 \cdot U_{3}\right)^{-0,3035}-0,002715 \cdot U_{3} \cdot\left(1+0,044 \cdot U_{3}+0.0003 \cdot U_{3}^{2}\right)^{-1}\right]$

Where $\mathrm{m}_{\mathrm{A}}$ (dimensionless) is the air mass at the actual pressure of the site, $m_{r}$ (dimensionless) is the air mass at standard pressure $(1013.25 \mathrm{mbar}), \mathrm{U}_{1}(\mathrm{~cm})$ is the pressurecorrected relative optical path length of precipitable water, $\mathrm{K}_{\mathrm{a}}$ (dimensionless) is the optical aerosol thickness and $\mathrm{U}_{3}$ $(\mathrm{cm})$ is the optical path relative to the ozone layer.

$$
\begin{aligned}
& m_{A}=\frac{1}{\sin (h s)+9,40 \cdot 10^{-4} \cdot[\sin (h s)+0,0678]^{-1,253}} \\
& m_{r}=m_{A} \cdot\left(\frac{p}{1013,25}\right)^{-1}
\end{aligned}
$$

$$
U_{1}=H p \cdot m_{r}
$$

$$
K_{a}=0,2758 \cdot K_{a \lambda_{1}}+0,35 \cdot K_{a \lambda_{2}}
$$

For

$$
\lambda_{1}=0.38 \mu m \text { and } \lambda_{2}=0,50 \mu m
$$

$$
K_{a \lambda i}=\beta_{A} \cdot \lambda i^{(-1,3)}
$$

$\lambda i(m)$ is the wavelength and $B_{A}$ the Angstrom turbidity coefficients. Table 3 gives the values of $B_{A}$ according to the type of site.

$$
U_{3}=L_{o z} \cdot m_{r}
$$

Table 1: Value of $\beta_{A}$ according to the site

\begin{tabular}{|l|c|}
\hline Climate zones & $\beta_{A}$ \\
\hline Rural site & 0,05 \\
\hline Urban site & 0,10 \\
\hline Industrial site & 0,30 \\
\hline
\end{tabular}

$P$ (mbar) is the local ai- pressure, $Z(m)$ is the altitude of studied site, $\operatorname{Loz}(\mathrm{cm})$ is the vertical ozone-layer thickness and $\mathrm{H}_{\mathrm{p}}(\mathrm{cm})$ is the precipitable water-vapor thickness. These parameters can be calculated by the following equations.

$$
\begin{aligned}
& P=1013 \cdot\left(1-2,257 \cdot 10^{-5} \cdot Z\right)^{5,26} \\
& L_{o z}=\frac{1}{9,4+0,9 \cdot m_{r}}
\end{aligned}
$$

Diffuse Solar Radiation $D\left(W / \mathrm{m}^{2}\right)$ at ground level is a combination of three components corresponding to Rayleigh scattering after the first pass through the atmosphere $\left(D_{r}\right.$ $\left.\mathrm{W} / \mathrm{m}^{2}\right)$; the aerosol dispersion after the first passage through the atmosphere $\left(D_{a}\left(W / m^{2}\right)\right.$ and the multi-reflection processes between the ground and the sky $D_{m} W / m^{2}$ ) All these components are given respectively by the equation following: 


$$
\begin{gathered}
D=D_{r}+D_{a}+D_{m} \\
D_{r}=\frac{0,79 \cdot I_{c s} \cdot \sin (h s) \cdot \tau_{o} \cdot \tau_{g} \cdot \tau_{w} \cdot \tau_{a a} \cdot 0,5 \cdot\left(1-\tau_{r}\right)}{1-m_{r}+m_{A}{ }^{1,02}} \\
D_{a}=\frac{0,79 \cdot I_{c s} \cdot \sin (h s) \cdot \tau_{o} \cdot \tau_{g} \cdot \tau_{w} \cdot \tau_{a a} \cdot F_{c} \cdot\left(1-\tau_{a s}\right)}{1-m_{r}+m_{A}{ }^{1,02}} \\
D_{m}=\frac{(21)}{1-\rho_{g} \cdot \rho_{a}}
\end{gathered}
$$

where hs $\left(^{\circ}\right)$ is the solar elevation; Isc $\left(\mathrm{W} / \mathrm{m}^{2}\right)$ is the solar constant; $\zeta_{\text {aa }}$ is the transmission factor of direct solar radiation due to aerosol absorption, $\zeta_{\text {as }}$ is the fraction of the incident radiation transmitted after the aerosol scattering effects, $\rho_{g}$ (dimensionless) is the ground albedo (set at 0.2 ) and $\rho_{a}$ (dimensionless) is the albedo of cloudless sky.

$$
\begin{aligned}
& \tau_{a a}=1-\left(1-\omega_{0}\right) \cdot\left(1-m_{A}+m_{A}{ }^{1,06}\right)\left(1-\tau_{a}\right) \\
& \tau_{a s}=\frac{\tau_{a}}{\tau_{a a}} \\
& \rho_{a}=0,0685+\left(1-F_{c}\right) \cdot\left(1-\tau_{a s}\right)
\end{aligned}
$$

$\omega_{0}$ (dimensionless) is the single-scattering albedo fraction of incident energy scattered to total attenuation by aerosols and it is taken to be $0.9, F_{c}$ is the diffusion fraction, it is equal to 0.84 .

Finally, the global radiation $G\left(\mathrm{~W} / \mathrm{m}^{2}\right)$ received on a horizontal surface can be written in the form of the following equation.

$$
G=I_{n} \cdot \sin (h)+D
$$

\section{Ghouard model}

Ghouard et al. (1977) model proposed empirical formulas, which are based on the disturbing factor evaluations depending on the atmospheric conditions and astronomical parameters [7]. The direct solar radiation by this model does not take into account the absorbed and reflected solar flux by the atmospheric components (water vapor, aerosols, ozone ...), and it is defined as follows:

$$
I=I_{c s} \cdot C_{t} \cdot A_{1} \cdot \exp \left(-\frac{A_{2}}{\sin (h s)}\right) \cdot \sin (h s)
$$

The diffuse solar radiation comes from all the space and has no privileged orientation; and it can be calculated as follows:

$$
D=I_{c s} \cdot C_{t} \cdot\left[0,271-0,2939 \cdot A_{1} \cdot \exp \left(-\frac{A_{2}}{\sin (h s)}\right)\right] \cdot \sin (h s)
$$

The global solar radiation can be calculated by the following equation:

$G=0,271 \cdot I_{c s} \cdot C_{t} \cdot A_{1} \cdot \sin (h s)+0,706 \cdot I_{c s} \cdot C_{t} \cdot A_{1} \cdot \sin (h s) \cdot \exp \left(-\frac{A_{2}}{\sin (h s)}\right)$

$C_{t}$ represents the Earth-Sun distance correction. It can be given by:

$$
C_{t}=1+0,034 \cdot \cos (n-2)
$$

Where, $\mathrm{n}$ is the day number of the year. Ics is the solar constant, A1 and A2 are the coefficients of the turbidity factor, and they are given in the following Table 2 .

Table 2: Turbidity factors depending on climatic conditions.

\begin{tabular}{|l|l|l|l|}
\hline $\begin{array}{l}\text { Climatic } \\
\text { condition }\end{array}$ & $\begin{array}{l}\text { Clear } \\
\text { sky }\end{array}$ & $\begin{array}{l}\text { Normal } \\
\text { condition }\end{array}$ & $\begin{array}{l}\text { Covered } \\
\text { sky }\end{array}$ \\
\hline A1 & 0.87 & 0.88 & 0.91 \\
\hline A2 & 0.17 & 0.26 & 0.43 \\
\hline
\end{tabular}

\section{Perrin-Brichambaut model}

In 1975, Perrin-Brichambaut proposed a model, which is a function of astronomical parameters [8]. The above relationships are transformed into the following ones according to the atmospheric conditions:

$$
\begin{gathered}
D=0,1 \cdot I_{c s} \cdot C \cdot(\sin (h s))^{0,4} \\
I=R \cdot \exp \left(\frac{-A}{B \cdot \sin (h s+1)}\right) \cdot \sin (h s) \\
G=I+D
\end{gathered}
$$

Where, $R\left(\mathrm{~W} / \mathrm{m}^{2}\right)$ is the apparent extraterrestrial irradiance. A, $B$ and $C$ (dimensionless) are empirical values to calculate the solar irradiance according to the Perrin Brichambaut model (Table 3). 
Table 3: R, A, B and C values according to the Perrin Brichambaut model.

\begin{tabular}{|l|l|l|l|l|}
\hline Atmospheric condition & R & A & B & C \\
\hline Clear sky & 1210 & 1,67 & 3,9 & 0,67 \\
\hline Normal condition & 1230 & 1,61 & 3,1 & 0,47 \\
\hline Industrial site & 1260 & 2,23 & 4 & 0,45 \\
\hline
\end{tabular}

\section{Dependent model of the Link trouble factor}

The Link trouble factor integrates several forms of attenuation, such as attenuation by clouds, aerosols, water vapor, etc.). These factors are widely used, in the case of missing data to estimate the attenuation of solar radiation for each component of the atmosphere. For this reason, models of solar radiation estimates often use this factor.

The global solar radiation on a horizontal plane given by the following equation:

$$
G=D+I
$$

Where I represents the solar radiation received on the horizontal plane without undergoing modification through the atmosphere. This component can be given by the following equation:

$$
I=I_{c s} \cdot \exp \left(\frac{-T_{L}}{0,9+9,4 \cdot \sin (h s)}\right) \cdot \sin (h s)
$$

Where, hs is the solar elevation, $T_{L}$ is the Link trouble factor given by the following equation:

$$
T_{L}=2,4+14,6 \cdot F_{T A}+0.4 \cdot\left(1+2 \cdot F_{T A}\right) \cdot \ln \left(P_{v}\right)
$$

$F_{T A}$ represents the atmospheric trouble factor. It can take several values depending on the atmospheric nature of the areas.

$F_{T A}=0,05$ in rural areas;

$F_{T A}=0,1$ in urban area;

$F_{T A}=0,2$ in industrial or polluted zone.

$P_{v}$ is the partial pressure of water vapor (expressed in $\mathrm{mmHg}$ ). It can be calculated by the following equation:

$$
P_{v}=\frac{760}{101325} \cdot\left(P_{a t}-P_{\mathrm{sec}}\right)
$$

With $\mathrm{P}_{\mathrm{at}}$ is the atmospheric pressure (in Pascal), $\mathrm{P}_{\mathrm{sec}}$ the dry air pressure, equal to $1,01222 * 10^{5} \mathrm{~Pa}$.

Diffuse solar radiation can be calculated by the following equation:

$$
D=0 \cdot 04 \cdot I_{c s} \cdot \sqrt{\sin (h s)} \cdot\left(T_{L}-0,5-\sqrt{\sin (h s)}\right)
$$

\section{Models performance validation}

In addition, the performance of the proposed model has been evaluated based on the following well established statistical error parameters [9]:

\section{Root Mean Square Error (RMSE)}

The RMSE $(\mathrm{W} / \mathrm{m} 2)$ is always positive, a zero value is ideal. This test provides information on the short-term performance of the models by allowing a term by term comparison of the actual deviation between the calculated value and the measured value [10]. It can be expressed by the following equation:

$$
R M S E=\sqrt{\frac{1}{k} \cdot \sum_{1}^{k}\left(G_{e S}-G_{m e S}\right)^{2}}
$$

\section{Mean Bias Error (MBE)}

The test of $\mathrm{MBE}\left(\mathrm{W} / \mathrm{m}^{2}\right)$ provides information on the long term performance of the models [11]. A positive MBE gives the average amount of over estimation in the predicted value and a negative MBE value gives the average amount of under estimation in the predicted value. It is given by the following equation:

$$
E M C M=\frac{1}{k} \cdot \sum_{1}^{k} G_{e s}-G_{m e s}
$$

\section{Coefficient of determination $R^{2}$}

The $R^{2}$ takes values between 0 and 1 . While a value around 1 shows perfect linear relationship between the measured and calculated values, a value around zero indicates the absence of the linear relationship [12]. This coefficient can be expressed by equation (41).

$$
\begin{aligned}
& R^{2}=1-\frac{\sum_{1}^{k}\left(G_{e s}-G_{\text {mes }}\right)^{2}}{\sum_{1}^{k}\left(G_{m e s}-\bar{G}_{m e s}\right)^{2}} \\
& \bar{G}_{m e s}=\frac{1}{k} \cdot \sum_{1}^{k} G_{m e s}
\end{aligned}
$$

$\mathrm{K}$ is the total number of observations, $\mathrm{G}_{\mathrm{es}}$ is the value estimated by the model, $G_{m e s}$ is the measured value.

\section{Results and analysis}

\section{Global solar energy available}

Measurements of global solar radiation collected in Nouakchott (Cheikh Zayed plant) are used to analyze the available solar potential. The application of available solar energy calculation methods and clearness index was used to determine solar 
energy and daily clearness index. The monthly average of these two parameters is calculated. The results obtained are given in Table 4. The results shows that solar energy available on the Nouakchott coast is quite large. The values obtained varies from $5023.07 \mathrm{Wh} / \mathrm{m}^{2} / \mathrm{d}$ (December) to $7117.18 \mathrm{Wh} / \mathrm{m}^{2} / \mathrm{d}$ observed for the month of April. The corresponding clearness indices are 0.67 for the two months, respectively. These results show the clarity of the sky during these two months (kt greater than 65\%). The results of the clearness index obtained (Table 4) show in the majority of cases $(75 \%$ of the time), that the clearness index corresponds to clear sky days. For the months of February, June and August, the clearness index is less than the clear-sky threshold. The values remain however high (higher than 60\%).

Table 4: Monthly average of extraterrestrial solar irradiation, global solar irradiance on ground and clearness index

\begin{tabular}{|l|c|c|c|}
\hline Months & $\begin{array}{l}\text { Solar } \\
\text { energy on the } \\
\text { ground } \\
\mathrm{G}\left(\mathrm{Wh} / \mathrm{m}^{2} / \mathrm{d}\right)\end{array}$ & $\begin{array}{c}\text { Solar energy } \\
\text { outside the } \\
\text { atmosphere } \\
\mathrm{G}^{\mathrm{h}}\left(\mathrm{Wh} / \mathrm{m}^{2} / \mathrm{j}\right)\end{array}$ & $\begin{array}{c}\text { Clearness } \\
\text { index K } \\
(-)\end{array}$ \\
\hline January & 5390,21 & 7807,94 & 0,69 \\
\hline February & 5472,16 & 8772,77 & 0,62 \\
\hline March & 6939,06 & 9851,57 & 0,70 \\
\hline April & 7117,18 & 10584,86 & 0,67 \\
\hline May & 7004,98 & 10845,87 & 0,65 \\
\hline June & 6640,87 & 10859,26 & 0,61 \\
\hline July & 6997,18 & 10792,69 & 0,65 \\
\hline August & 6510,48 & 10566,52 & 0,62 \\
\hline September & 6840,42 & 9938,71 & 0,69 \\
\hline October & 6076,91 & 8917,93 & 0,68 \\
\hline November & 5348,61 & 7910,39 & 0,67 \\
\hline December & 5023,07 & 7455,46 & 0,67 \\
\hline
\end{tabular}

\section{Distribution of available solar energy}

The data collected on the Nouakchott coast are also used to study the distribution of available solar energy. The daily solar energies calculated from these measurements are therefore used. The frequency and cumulated frequency of each energy varies from 0 to $9 \mathrm{kWh} / \mathrm{m}^{2} / \mathrm{d}$ in steps of 0.5 are determined. The results obtained are illustrated in figure 2 (a and b). Figure2 (a) shows that daily solar energy is available at different frequencies. These energies vary between 1 and 8 $\mathrm{kWh} / \mathrm{m}^{2} / \mathrm{d}$. For energy variations in the interval between 0 and $4 \mathrm{kWh} / \mathrm{m}^{2} / \mathrm{d}$, the available frequencies are low (less than or equal to $1.5 \%)$. On the other hand, for energy variations in the interval between 4 and $8 \mathrm{kWh} / \mathrm{m}^{2} / \mathrm{d}$, the frequency of the energy is between 6 and $22 \%$. The highest frequency (22\%) is obtained for the daily energy of $7 \mathrm{kWh} / \mathrm{m}^{2} / \mathrm{d}$. These results show that a PV generator installed on the Nouakchott coast can operate at a rate of $22 \%$ with available solar energy of 7 $\mathrm{kWh} / \mathrm{m}^{2} / \mathrm{d}$. The results of the cumulated distribution (Figure 2 (b)) show that the daily energies frequency less than or equal to $5 \mathrm{kWh} / \mathrm{m}^{2} / \mathrm{d}$ is $6 \%$, which means that during $94 \%$ of time, a PV generator can operate at available solar energy above 5 $\mathrm{kWh} / \mathrm{m}^{2} / \mathrm{d}$. This value is greater than average solar energy in many parts of the world [5].

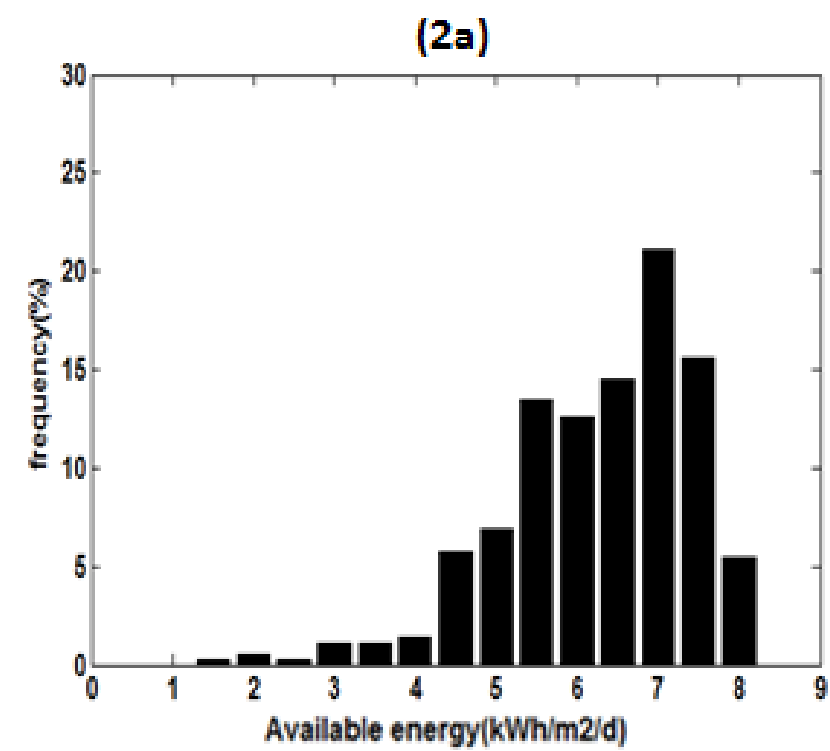

(2b)

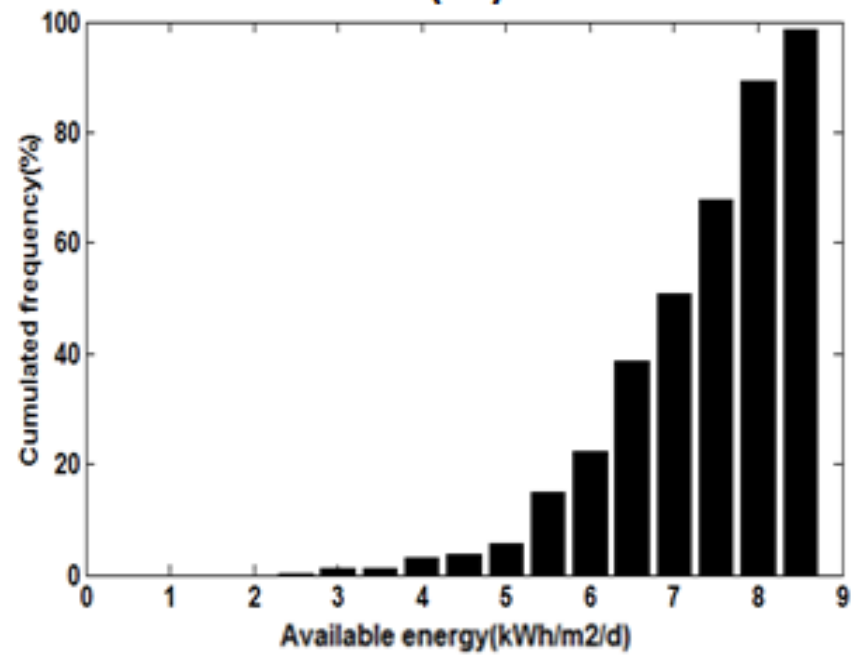

Figure 2 (a), (b): Daily distribution of available solar energy 


\section{Analysis of the clearness indices distribution}

The results obtained from daily clearness index calculations are used to analyze the distribution. Thus, the frequency distribution and the cumulated distribution are indicated in figure 3 ( $a$ and $b$ ). It can be seen that there nearly exist no clearness index between 0 and 0.35 , the frequency observed in this interval being $1.5 \%$ at most. For the clearness index between 0.35 and 0.65 , the observed frequency can reach $25 \%$. The highest frequency is observed for the clearness index greater than $65 \%$. Indeed, the figure (3b) of the cumulated distribution illustrates that the frequency for which clearness index is less than or equal to 0.65 is about $25 \%$, so $75 \%$ of the time represents a clearness index greater than 0.65 . We can say that $75 \%$ of the time, the sky is clear with a cloud cover almost nil. This is interesting for a photovoltaic or thermal application using global solar radiation.

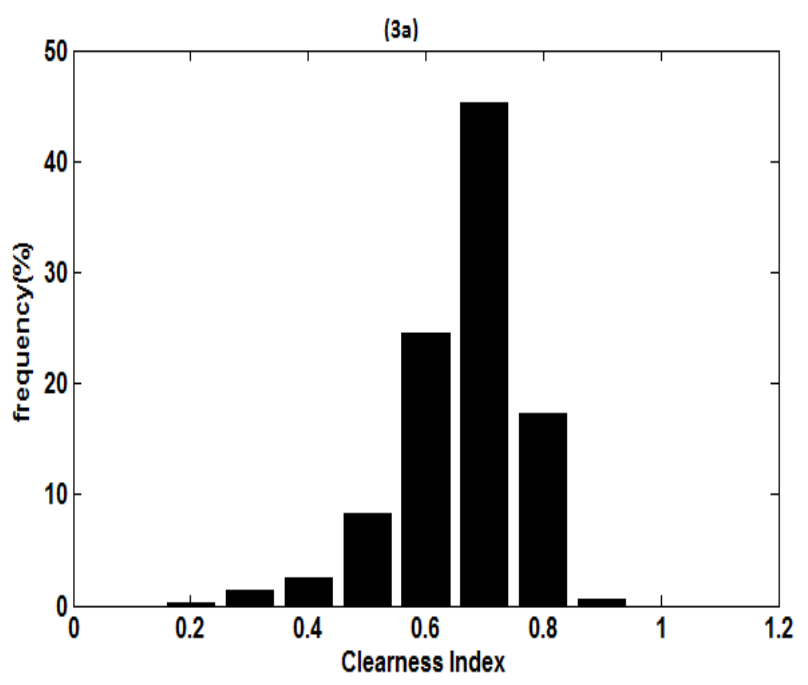

(3b)

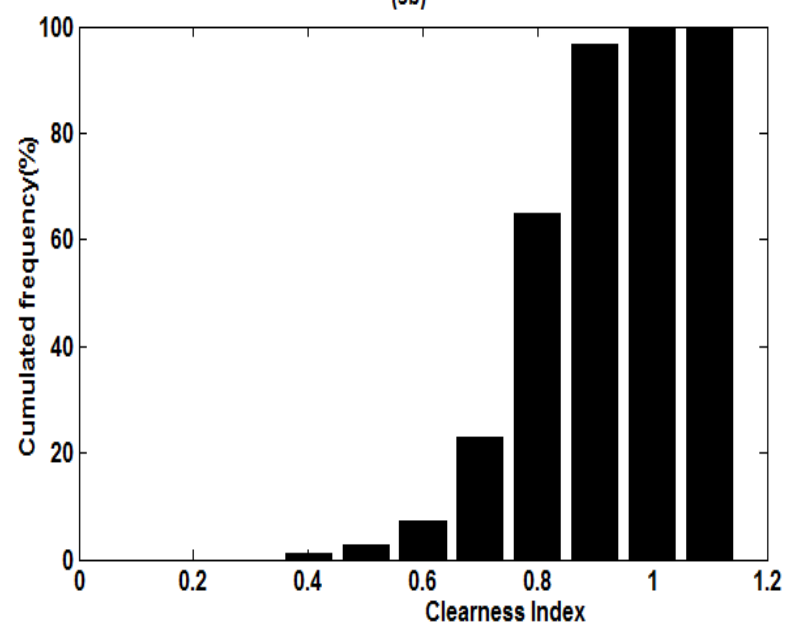

Figure 3 (a), (b): Distribution of the clearness index

\section{Model performance analysis}

This study part presents the results obtained on solar radiation modeling. The four models presented above are studied by determining the solar radiation in steps of 5 minutes for cases of clear sky days where $\mathrm{Kt}$ is greater than or equal to $65 \%$. The results obtained as a result of the calculation are compared with the measurements corresponding to the measurement period. Thus, the parameters of performance analysis of the models such as the root mean square error, the coefficient of determination, the mean error between the measurements and the predicted values are determined for each model. The results obtained are shown in Table 5 .

Table 5: Model Performance Parameters

\begin{tabular}{|l|c|c|c|}
\hline \multicolumn{1}{|c|}{ Type of Models } & MBE $\left(\mathrm{W} / \mathrm{m}^{2}\right)$ & $\mathrm{RMSE}\left(\mathrm{W} / \mathrm{m}^{2}\right)$ & $\mathrm{R}^{2}(-)$ \\
\hline Ghouard & $-0,54$ & 79,69 & 0,962 \\
\hline Trouble of Link & $-4,83$ & 79,74 & 0,960 \\
\hline Bird and Hulstrom & 5,88 & 81,66 & 0,959 \\
\hline $\begin{array}{l}\text { Perrin- } \\
\text { Brichambaut }\end{array}$ & $-40,78$ & 102,83 & 0,935 \\
\hline
\end{tabular}

The results (Table 5 ) show that the models give good results with a coefficient of determination greater than $93 \%$. It should be noted that the Ghouard model gives, however, better results with a mean error of $0.54 \mathrm{~W} / \mathrm{m} 2$, a root mean square error of $79.69 \mathrm{~W} / \mathrm{m}^{2}$ and the corresponding coefficient of determination of $96.2 \%$. The results also shows that the highest errors are observed for the Perrin-Brichambaut model, so the Perrin Brichambaut model is the worst performer at the Nouakchott site. The observed errors are 40.78 and 102.83 $\mathrm{W} / \mathrm{m}^{2}$ for the mean error and mean squared error respectively. The corresponding coefficient of determination is $93.5 \%$. These results are comparable to those found in reference [7]. We also find that Ghouard, Perrin-Brichambaut models and the dependent model of Link trouble factor underestimate the measures, and the Bird and Hulstrom model overestimate the measures. Figure 4 illustrates the pace of the solar radiation calculated by the four models and the measured solar radiation. These results represent the solar radiation of a typical clear-sky day, calculated over the period of the year after having subtracted $25 \%$ of the data corresponding to the averagely covered sky and / or covered corresponding to $\mathrm{Kt}$ lower than $65 \%$. It can be noted that the times of sunrise and sunset correspond for all the models and the measurements as well as the time of the maximum solar radiation. The maximum observed difference between the measured and calculated solar radiation is $16.67 \%$, for the Perrin Brichambaut model and the minimum difference is $7.7 \%$ observed for the Ghouard model.

Solar radiation calculated and measured for days with clear skies are also used to analyze the distribution. The cumulated distribution is then determined for the four models and for the 
measurements. The results obtained are illustrated in figure 5. It can be seen that solar radiation less than or equal to $500 \mathrm{~W} / \mathrm{m}^{2}$ is available at a time percentage between $50 \%$ (model using the Link trouble factor) and $70 \%$ (PerrinBrichambaut). The percentage corresponding to the measurements is about $65 \%$. For solar radiation greater than $500 \mathrm{~W} / \mathrm{m}^{2}$, the time percentage is $50 \%, 30 \%$ and $45 \%$ for the three cases (model using the Link trouble factor, Perrin-Brichambaut model and the measurements) respectively.

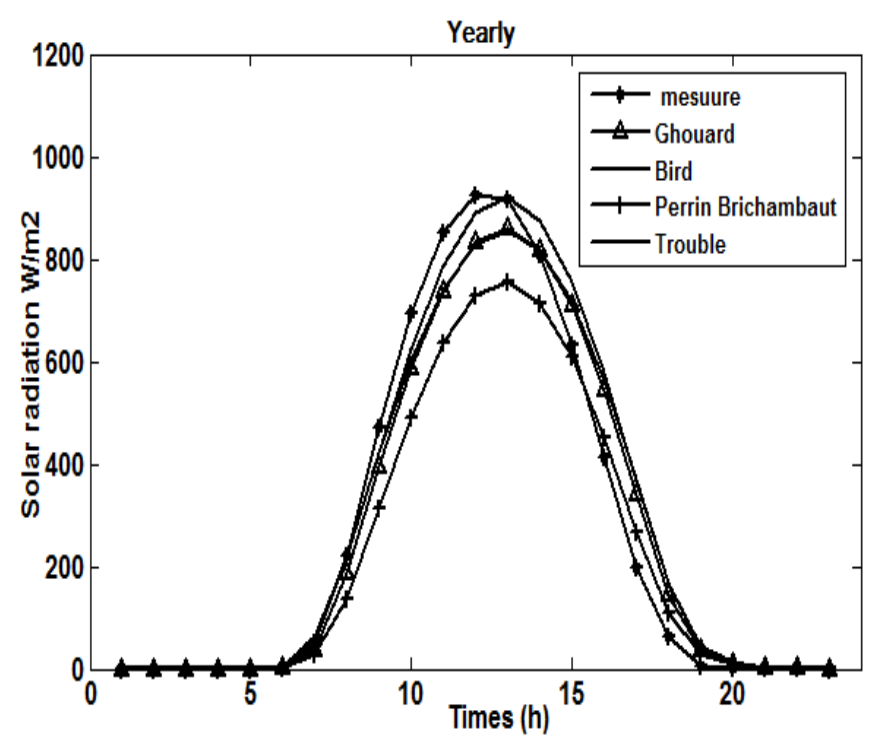

Figure 4: Solar radiation measured and calculated as a function of time

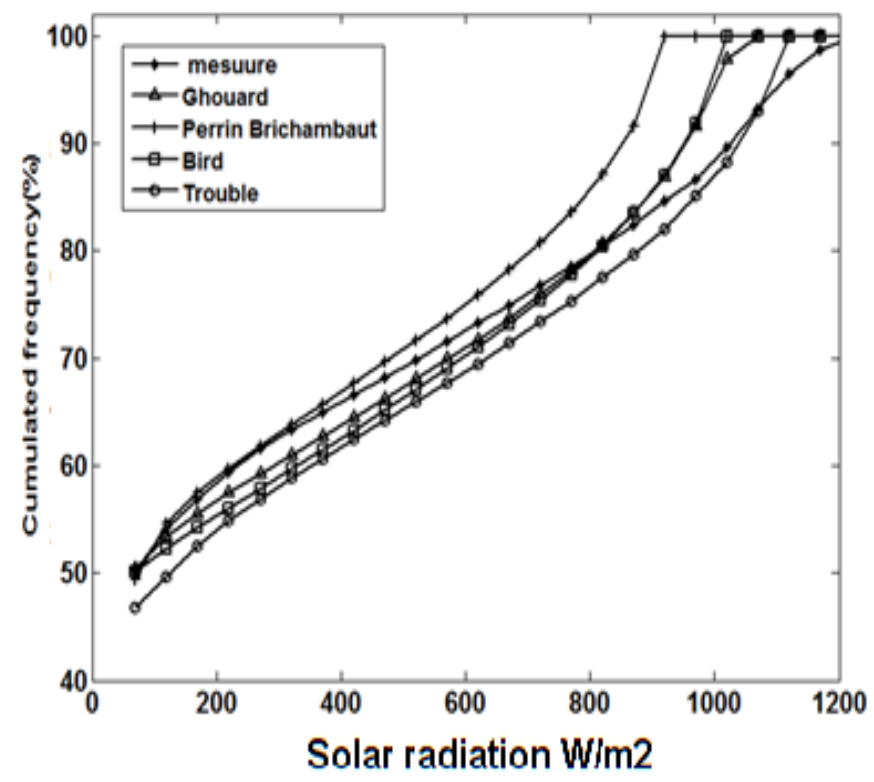

Figure 5: Cumulated distribution of solar radiation

\section{Calculated and measured solar energy}

The solar radiation calculated for each model over one year period has been used to estimate the solar potential available. Thus, the available daily solar energy is calculated on the period of each month using the equation 1 , the results of the calculations are presented in figure 6 . The results show that the calculated solar energies follow the same pace for all models with a significantly difference between the models. On the other hand, the measured solar energy shows a significant and stable potential for the months of September, October, November, December and January. These high values of available solar energy observed for measurements can be explained by the significance of the solar radiation intensity essentially due to a lack of cloud cover and low attenuation of solar radiation during the indicated period. Indeed, the clearness index observed for these months is greater than $65 \%$, which corresponds to days with clear skies.

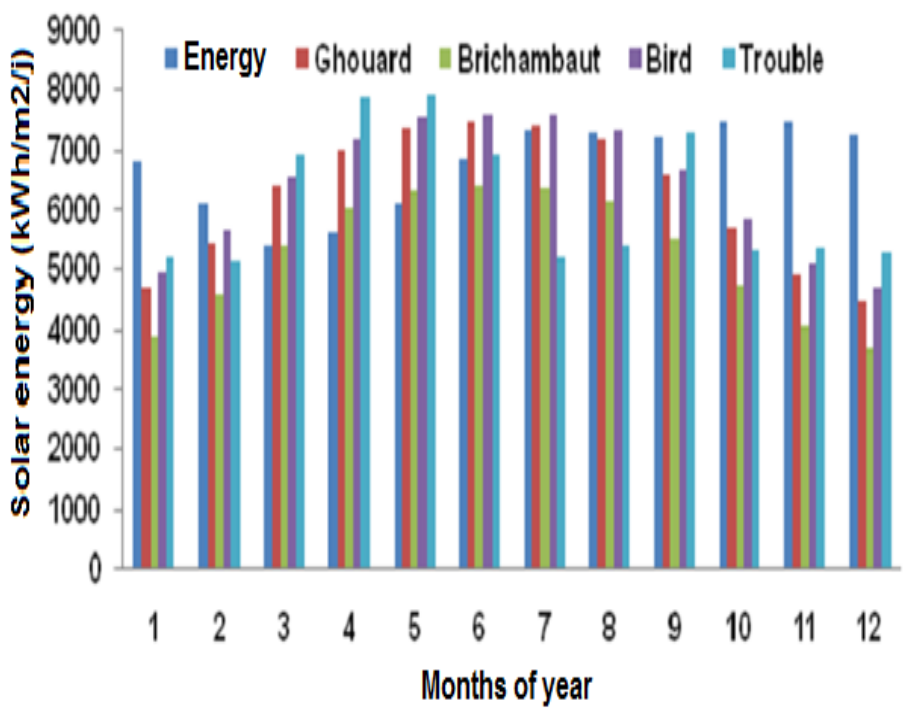

\section{Figure 6: Measured and calculated monthly solar energy variation}

\section{Distribution of calculated energies}

The energy calculated for clear-sky days is also used to determine the available energy distribution by taking into account the same step of variation of previously adopted energies. The results obtained are illustrated by figure 7 . It can be seen that for energies less than or equal to 5 $\mathrm{kWh} / \mathrm{m}^{2} / \mathrm{d}$, the frequency is equal to zero. This can be explained that the days whose energy is less than 5 $\mathrm{kWh} / \mathrm{m}^{2} / \mathrm{d}$ corresponds to covered or averagely covered sky, so are not taken into account in the calculation. 

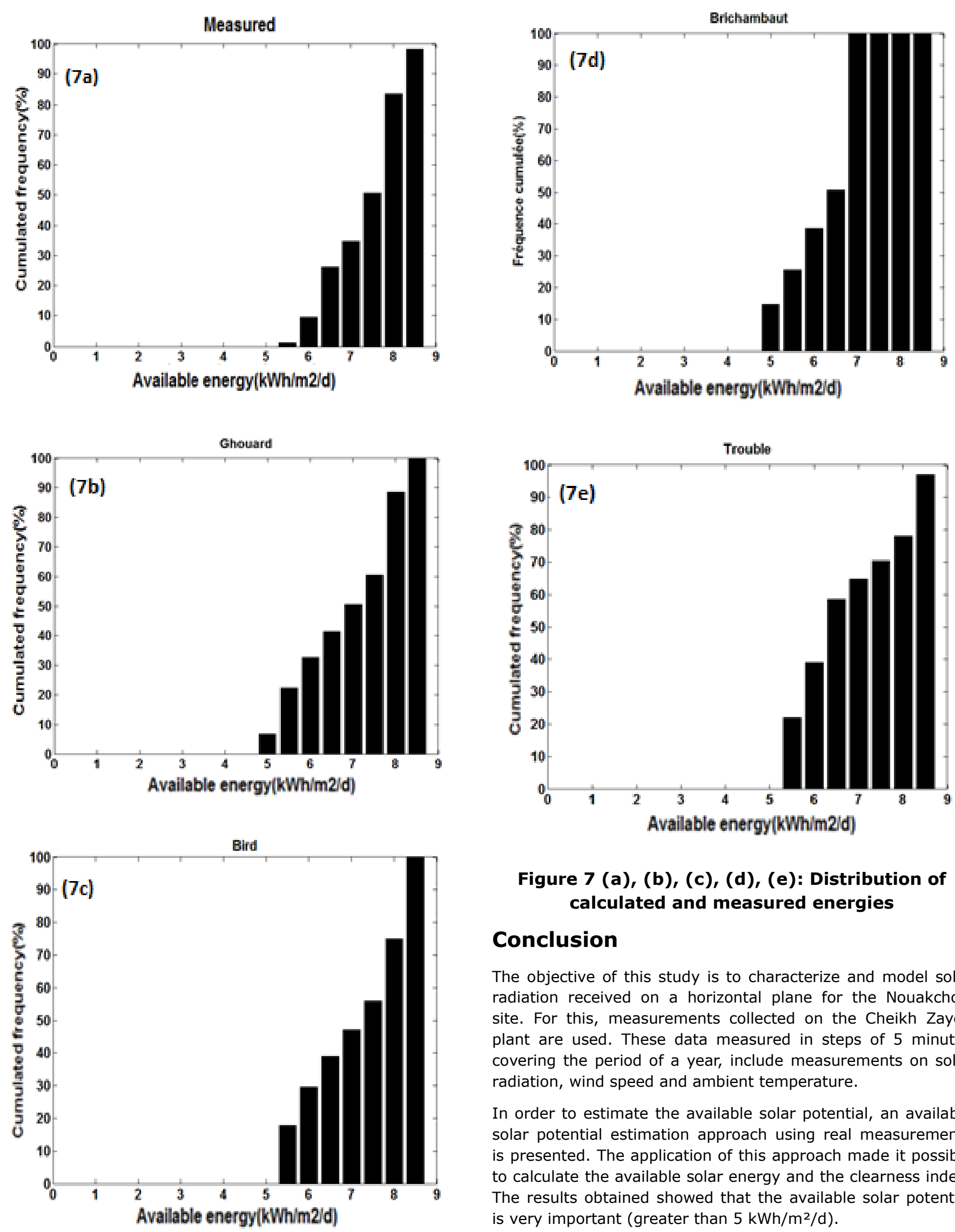

Figure 7 (a), (b), (c), (d), (e): Distribution of

\section{Conclusion}

The objective of this study is to characterize and model solar radiation received on a horizontal plane for the Nouakchott site. For this, measurements collected on the Cheikh Zayed plant are used. These data measured in steps of 5 minutes covering the period of a year, include measurements on solar radiation, wind speed and ambient temperature.

In order to estimate the available solar potential, an available solar potential estimation approach using real measurements is presented. The application of this approach made it possible to calculate the available solar energy and the clearness index. The results obtained showed that the available solar potential is very important (greater than $5 \mathrm{kWh} / \mathrm{m}^{2} / \mathrm{d}$ ). 
In order to choose an appropriate model to predict the solar radiation available on a horizontal plane for the Nouakchott region, four of the most used models in the literature are presented. There is the model of Ghouard, PerrinBrichambaut, Bird and Hulstrom and the model dependent on the Link trouble factor. The performance of these four models is also studied by determining the determination coefficient, the mean squared error and the mean error between the calculated value and the measured value. The performance analysis is performed considering the one-year period of measurements.
The results obtained showed that, overall, the models give good results (with a coefficient of determination (R2) greater than $93 \%$ ). These models can, therefore, be used to estimate global solar irradiance for Nouakchott site and for locations with climates similar. In this study, we showed that the best results are however obtained with the Ghouard model.

In perspective, it is important to characterize and model the available solar potential using a longer period (10 years) and for other regions of Mauritania and sub-regions to take into account the influence of spatiotemporal variation on the available potential and on the quality of solar radiation modeling.

\section{Complementary informations on authors:}

Ahmed Sidibba: sidiabaahmed@gmail.com, Research Gate (Ahmed Sidibba)

Boudy Bilal: boudy bilal@yahoo.fr, Research Gate (Boudy Bilal),

Diene Ndiaye: diene.ndiaye@ugb.edu.sn, Research Gate (Diene Ndiaye)

Sidi Bouhamady: sbouhamady@gmail.com,

Menny El Bah: mennyfr@yahoo.fr,

\section{REFERENCES}

[1]Samira MC. Statistical study of solar radiation on an inclined plane, thesis defended in 2012 in the University of Aboubeker Belkaid.

[2] M. Capderou, 'Solar Atlas of Algeria, Tome 1, Vol 1 and 2: Theoretical and Experimental Models', University Publications Offices, Algeria, 1987.

[3] Zhang QY. Huang YJ. Development of typical year weather files for Chinese locations. ASHRAE Transactions 2002; 108(2):1063-75.

[4] Chen, R., K. Ersi, J. Yang, S. Lu and W. Zhao. Validation of five global radiations models with measured daily data in China. Energy Conversion and Management 2004, 45:1759-69.

[5] Bilal B. Implementation of new multi-objective optimization approaches for hybrid wind-solar-battery-generator systems. University Thesis, ESP-UCAD, 2012, No19, 145p.

[6] Bird RE, Hulstrom RL. A simplified clear sky model for direct and diffuse insolation on horizontal surfaces. Golden, CO: Solar Energy Research Institute; 1981 SERI/TR-642-761.

[7] Mghouchi Y. El Bouardi A., Choulli Z., Ajzoul T., Models for obtaining the daily direct, diffuse and global solar radiations .Renewable and Sustainable Energy Reviews, 2016, 56, 87-99.

[8] Perrin de Brichambaut C. 'Estimation of Energy Resources in France', 1975, Notebooks of the A.F.E.D.E.S, N ${ }^{1 .}$

[9] Stone RJ. Improved statistical procedure for the evaluation of solar radiation estimation models. Sol Energy 1993;51(4):289-91. 
[10] Katiyar A.K., Kumar A., Pandey C.K. and Das B. A Comparative Study of Monthly Mean Daily Clear Sky Radiation over India', International Journal of Energy and Environment, IJEE, Vol. 1, №1, pp. 177 - 182, 2010.

[11] Zekai Sen, 'Solar Energy Fundamentals and Modelling Techniques', Edition Springer, 2008.

[12] Kerkouche K., Cherfa F., Hadj A., Arab Bouchakour S., Abdeladim K. et Bergheul K., Evaluation of the global solar irradiation on an inclined surface according to different models for the site of Bouzaréah, Revue of Renewable Energies Vol. 16 No. 2, 2013, 269-284. 
Important: Articles are published under the responsability of authors, in particular concerning the respect of copyrights. Readers are aware that the contents of published articles may involve hazardous experiments if reproduced; the reproduction of experimental procedures described in articles is under the responsability of readers and their own analysis of potential danger.

\section{Reprint freely distributable - Open access article}

Materials and Devices is an Open Access journal which publishes original, and peer-reviewed papers accessible only via internet, freely for all. Your published article can be freely downloaded, and self archiving of your paper is allowed and encouraged!

We apply «the principles of transparency and best practice in scholarly publishing » as defined by the Committee on Publication Ethics (COPE), the Directory of Open Access Journals (DOAJ), and the Open Access Scholarly Publishers Organization (OASPA). The journal has thus been worked out in such a way as complying with the requirements issued by OASPA and DOAJ in order to apply to these organizations soon.

Copyright on any article in Materials and Devices is retained by the author(s) under the Creative Commons (Attribution-

NonCommercial-NoDerivatives 4.0 International (CC BY-NC-ND 4.0)), which is favourable to authors.

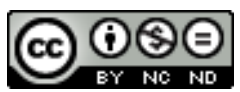

Aims and Scope of the journal : the topics covered by the journal are wide, Materials and Devices aims at publishing papers on all aspects related to materials (including experimental techniques and methods), and devices in a wide sense provided they integrate specific materials. Works in relation with sustainable development are welcome. The journal publishes several types of papers : A: regular papers, L : short papers, R : review papers, $\mathrm{T}$ : technical papers, Ur : Unexpected and « negative » results, Conf: conference papers.

(see details in the site of the journal: http://materialsanddevices.co-ac.com)

We want to maintain Materials and Devices Open Access and free of charge thanks to volunteerism, the journal is managed by scientists for science! You are welcome if you desire to join the team!

Advertising in our pages helps us! Companies selling scientific equipments and technologies are particularly relevant for ads in several places to inform about their products (in article pages as below, journal site, published volumes pages, ...). Corporate sponsorship is also welcome! 